\title{
Rádio em ambientes digitais: experiências de segmentação em aplicativos para dispositivos móveis
}

\author{
Radio in digital environments: segmentation \\ experiences in mobile devices apps
}

\begin{abstract}
Sônia Caldas Pessoa | Universidade Federal de Minas Gerais (UFMG) Professora do Programa de Pós-graduação em Comunicação Social (PPGCOM) da Universidade Federal de Minas Gerais (UFMG), doutora em Estudos Linguísticos (UFMG) Pesquisadora do Núcleo de Pesquisa em Conexões Intermidiáticas (NucCon)/Centro de Convergência em Novas Mídias (CCNM/UFMG). Email: soniacaldaspessoa@gmail.com..
\end{abstract}

Nair Prata | Universidade Federal de Minas Gerais (UFMG) Jornalista (UFMG), doutora em Linguística Aplicada (UFMG), professora do curso de Jornalismo e do Programa de Pós-Graduação em Comunicação e Temporalidades da Universidade Federal de Ouro Preto (UFOP), diretora Regional Sudeste da Intercom, vice-presidente da Associação Brasileira de Pesquisadores de História da Mídia (Alcar), membro do Grupo de Pesquisa Convergência e Jornalismo (Conjor). Email: nairprata@uol.com.br.

Kamilla Avelar | Centro Universitário de Belo Horizonte (UniBH) Jornalista pelo Centro Universitário de Belo Horizonte (UniBH), doutoranda em Administração pela Universidade Fumec, mestra pelo programa de Pós-Graduação em Comunicação e Temporalidades pela Universidade Federal de Ouro Preto (PPGCOM/UFOP), especialista em Gestão de Marketing pela Fundação Dom Cabral, membro do Grupo de Pesquisa Convergência e Jornalismo (Conjor)

Email: kamilla_avelar@yahoo.com.br.

\section{Resumo}

A presente pesquisa realiza um estudo de caso de uma rádio transmitida por meio do aplicativo WhatsApp e suas dinâmicas interativas em páginas em redes sociais online. Entre os objetivos deste estudo de inspiração etnográfica de uma rádio segmentada estão a descrição e análise dos processos de transmissão, circulação da produção de textos audioverbovisuais, modelo de negócio e interação com os ouvintes usuários do aplicativo. Pretende-se compreender possíveis experiências de pessoas comuns em ambientes digitais que provocam tensóes entre os modos de fazer rádio, as tecnologias digitais, a visibilidade e o suposto empoderamento do ouvinte. Palavras-chave: rádio; WhatsApp; textos audioverbovisuais; empoderamento do ouvinte; modelo de negócios.

\begin{abstract}
TThis research accomplishes a case study of a radio transmitted through WhatsApp and its interactive dynamics on pages in social networks online. Among the objectives of this ethnographic study of a segmented radio are the description and analysis of the processes of transmission, circulation of the production of audioverbvisual texts, business model and interaction with the listeners that use the application. It seeks to understand possible experiences in digital environments that provoke tensions between the ways of doing radio, the digital technologies, the visibility and the supposed empowerment of the listener.
\end{abstract}

Keywords: radio, WhatsApp, audioverbvisuals texts; listener empowerment; business model. 


\section{Traçados iniciais da pesquisa}

Os apontamentos que vamos desenvolver neste artigo partem de reflexôes teórico-metodológicas que articulam estudos anteriores realizados por estas pesquisadoras em rádios em ambientes digitais. A centralidade das discussóes está nos atravessamentos entre o empoderamento sutil do ouvinte (PESSOA, 2016), a segmentação de produção em áudio (PRATA; MARTINS, 2015) e modelos de negócios (PRATA; MARTINS, 2010; AVELAR; PRATA, 2016). Promovemos um diálogo com outros autores (ORTIZ-SOBRINO, 2017) que pensaram configuraçóes possíveis para essas produções que se apresentam como iniciativas de pessoas comuns para emissoras de rádio.

Optamos por realizar uma pesquisa de inspiração etnográfica, com observação não participante em transmissôes de áudio, que se autointitulam rádio, por meio do aplicativo WhatsApp, considerado por MartinezCosta e Prata (2016) como uma das plataformas sociais de emissão radiofônica. Lembramos que, com a expansão da internet e a migração do bolo publicitário, o rádio tem experimentado novos modos de produzir e modelos de negócio em ambientes digitais. Essas experiências têm sido registradas em diversas pesquisas que são referência para o mercado de Comunicação. Entre elas, destacamos três que consideramos importantes por relacionarem o acesso à internet aos celulares apontando o WhatsApp como um dos aplicativos preferidos pelos brasileiros.

A Pesquisa Brasileira de Mídia 2016ํㅜ revela que aproximadamente duas em cada três pessoas entrevistadas conectam-se à internet e o celular é o dispositivo mais utilizado para acessar a rede. O tempo médio de acesso diário, considerados sete dias da semana, está um pouco acima de 4 h30min. O Instituto Nielsen, por sua vez, informou que $75 \%$ dos usuários que utilizam o smartphone navegam pelas redes sociais, 39\% escutam música online e em streaming e $74 \%$ acessam aplicativos ${ }^{2}$. De acordo com o relatório da startup Opinion Box, o WhatsApp é o aplicativo mais encontrado na tela principal de $84,7 \%$ dos brasileiros e foi apontado como o favorito por quase metade dos entrevistados, $44,9 \%{ }^{3}$.

Apesar de tomarmos o WhatsApp como aplicativo para transmissão de produção em áudio como referência para esta pesquisa, consideramos que a observação apenas neste aplicativo não seria suficiente para a compreensão das dinâmicas interativas que se estabelecem entre a rádio e os ouvintes. Tendo em vista que o material da rádio tem potência para circulação em outros ambientes digitais tais como o Instagram e o Facebook, que são usados pela emissora, decidimos considerar também textualidades nestas plataformas digitais usadas para a circulação de conteúdos. Conforme Ortiz-Sobrino (2017), em apenas 20 anos, a internet associada à telefonia móvel e às redes sociais tem transformado o panorama radiofônico, introduzindo novos conceitos e formatos de rádio, sendo necessários outros suportes, linguagens e um novo modelo produtivo e comercial que considere esse cenário, renovando a oferta de programação, distribuição e consumo. 
Assim, nossa pesquisa realiza um estudo de caso de uma rádio transmitida por meio do aplicativo WhatsApp e suas dinâmicas interativas em páginas em redes sociais online. Entre os objetivos deste estudo de uma rádio segmentada estão a descrição e a análise dos processos de transmissão, circulação da produção de textos audioverbovisuais, modelo de negócios e interação com os ouvintes usuários do aplicativo. Pretendese compreender possíveis experiências em ambientes digitais que provocam tensôes entre os modos de fazer rádio, as tecnologias digitais e o empoderamento sutil do ouvinte.

\section{Escolhas metodológicas}

Nossos passos iniciais para a escolha da Rádio Web Clube Sertanejo, que reivindica para si o título de "primeira rádio via WhatsApp do mundo”, foram guiados por um levantamento exploratório em emissôes de áudio em ambientes digitais. Partimos de casos listados por MartinezCosta e Prata (2016) como novos modelos de escuta e de consumo e recortamos, para este estudo de caso, uma das emissóes que figuram entre experiências de rádio em ambientes digitais prioritariamente transmitidas por aplicativos instalados em dispositivos móveis.

Para realizar a pesquisa, optamos por observação e coleta de dados utilizando o celular. O período de análise está concentrado entre os dias 13 e 20 de março de 2017, de segunda-feira a domingo, tendo sido escolhido aleatoriamente, mas de modo que pudesse formar uma unidade de análise. Registramos que nos dias 11 (sábado) e 12 de março (domingo) a rádio enviou mensagens aos ouvintes sobre o retorno aos trabalhos após um período de férias. Foi coletado um conjunto de textos em áudio, verbais e visuais, capaz de articular significaçôes e sentidos vindos de situaçóes diversas e de relacionar textualidades distintas promovendo afetos e estimulando experiências diversificadas (MENDONÇA, 2010).

Nossa escolha por considerar essas textualidades diversas, e não apenas as emissóes em áudio, se dá em função de pesquisas de inspiração etnográfica em ambientes digitais nas quais chegou-se à conclusão que se tornam importantes a circulação e as dinâmicas entre inúmeras redes sociais online para a compreensão não só do objeto de estudo, mas dos fenômenos a ele articulados (PESSOA, 2015). Ao todo, reunimos oito emissóes em áudio realizadas pela rádio por meio do WhatsApp, 28 postagens no Instagram - deste total, três são vídeos -, 21 postagens no Facebook, com apenas um vídeo e nenhuma postagem no site da emissora. Além desta observação, realizamos entrevista em profundidade com o proprietário da Rádio Web Clube Sertanejo, Ademar Nunes Filho, utilizando o próprio WhatsApp e também o e-mail como ferramentas para a coleta das respostas.

Em nossa observação exploratória, registramos algumas iniciativas de rádio por meio do WhatsApp. Podemos destacar pelo menos dois formatos de produção. Um deles é feito por meio do envio de um programa 
diário gravado e editado, precedido por um breve texto que resume o tema a ser abordado. O outro prevê conjuntos de textos que, para além dos recursos sonoros, incluem recursos imagéticos e verbais, constituindo um encadeamento de elementos que nos apontam para outros formatos, diferentes daqueles que circulam no rádio hertziano, explorando ambientes digitais.

É neste segundo perfil que incluímos a Rádio Web Clube Sertanejo, aqui analisada. Como dissemos, ela divulga ser a primeira rádio do mundo via WhatsApp. Perguntamos ao proprietário da emissora, Ademar Filho, porque a emissora toma para si o pioneirismo nas transmissóes pelo aplicativo e a resposta foi a seguinte: "Só fazer pesquisa no Google que ali dá todas as informaçóes". Seguimos a indicação de pesquisa na internet, mas não encontramos dados precisos que nos permitem comprovar essa afirmação. Decidimos considerá-la, portanto, como a rádio que se autointitula a primeira via WhatsApp.

\section{De brincadeira de pessoas comuns a rádio por aplicativo}

A Rádio Web Clube Sertanejo foi fundada em 21 de maio de 2015. Sua história começou com uma brincadeira de um grupo de amigos, que gravaram áudios com músicas e notícias do mundo sertanejo. O dono e idealizador da rádio é Ademar Nunes Filho. Segundo ele próprio informou, estudou até o Ensino Médio e tem pouca experiência em rádio. De algum modo, podemos dizer que a iniciativa de Ademar nos remete às experiências do homem ordinário ou dos comuns, nas palavras de Certeau (2014), para quem, em determinadas situaçóes, este homem toma para si o papel de narrador, a partir de uma definiçáo de um lugar (comum) do discurso e o espaço do seu desenvolvimento. Um dos pontos, para além das reflexóes sociopolíticas e culturais, que diferenciariam a experiência de Ademar dos comuns de Certeau seria a ausência de anonimato neste espaço de desenvolvimento do discurso. Pelo contrário, teríamos a busca e o reforço da visibilidade sustentada pelas transmissóes e pela circulação dos conteúdos em redes sociais.

A primeira transmissão da emissora se deu durante 4 minutos e 21 segundos, com um áudio com músicas e notícias do mundo sertanejo. Os primeiros tempos seriam de testes, que resultaram em um segundo dia, no qual a então Rádio Clube da Viola permaneceu no ar por $9 \mathrm{mi-}$ nutos e 38 segundos. Ao final do primeiro mês, a rádio mudou de nome, passando a se chamar Rádio Zap Clube da Viola, com uma média de transmissão diária de 10 minutos. De acordo com o site da emissora ${ }^{4}$, "A brincadeira foi ficando séria, a rádio já estava ganhando muitos admiradores e com isso aumentando sua popularidade. Tivemos que adquirir mais conhecimentos, mais equipamentos e ferramentas para engrandecer a mesma e transmiti-la para ouvintes em todos os Estados do Brasil”. 

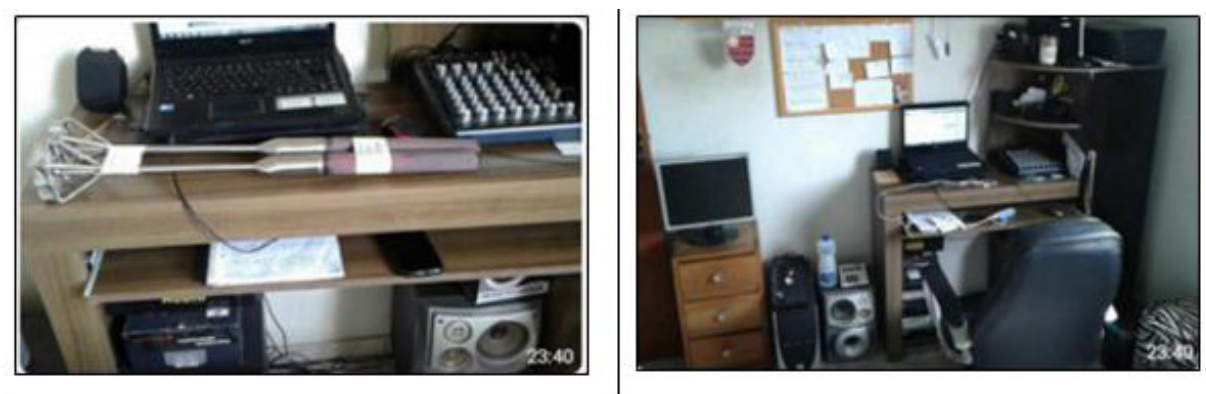

Figura 1: Redação/estúdio da rádio nos primeiros tempos

Fonte: Ademar Nunes Filho

A iniciativa desta rádio parece nos indicar que as mudanças trazidas pela convergência das mídias e pelo desenvolvimento das tecnologias digitais, que alteram permanentemente as formas de comunicação, dão condiçôes a pessoas comuns de compartilhar as próprias experiências em áudio com outras pessoas. Contemporaneamente, não há fronteiras para a distribuição do conteúdo multimídia, que pode figurar em diversos suportes ao mesmo tempo, ser consumido em qualquer horário, lugar e de forma simultânea. Ortiz-Sobrino (2017) afirma que, em apenas duas décadas, a internet, a telefonia móvel, os aplicativos e as redes sociais modificaram substancialmente o panorama radiofônico, redimensionando a estrutura da indústria da radiodifusão para uma nova maneira de entender os formatos dos programas e as formas de distribuição.

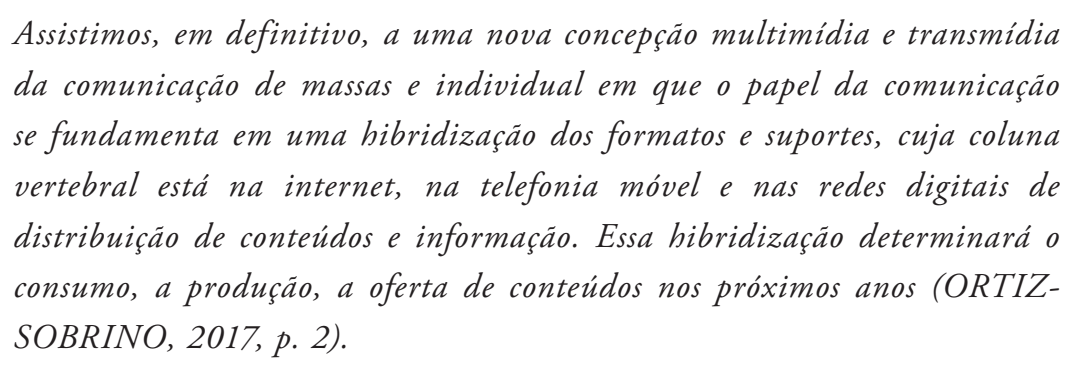

A concepção dos produtos, no entanto, está necessariamente relacionada aos termos de uso dos suportes. No caso em análise, por exemplo, os limites de tamanho de arquivo e de áudio do aplicativo impuseram restriçóes também na concepção da rádio, que pode usar, por vez, 16 megabytes (MB) e/ou 22 minutos de gravaçóes de áudio. "Passou de $16 \mathrm{MB}$ o áudio não entra. Então, quando iniciei, fui testando até chegar ao limite. Porém, se eu descer o KBPS, na hora de salvar a qualidade cai muito, então prefiro ficar com o padrão mesmo", explica Ademar Filho. Esse limite pode ser um dos fatores que impulsionaram a rádio a adotar as transmissóes $24 \mathrm{~h}$ por dia também por meio do site, o que teria ocorrido, segundo a divulgaçáo institucional da emissora, a pedido de amigos e ouvintes. Em 21 de dezembro de 2015, o nome da emissora sofreu nova modificação passando a ser Rádio Web Clube Sertanejo. Na sequência, desde 21 de janeiro de 2016, foram iniciadas as transmissóes pelo site. 
A elaboração deste produto, tanto do ponto de vista do conteúdo quanto da transmissão e da circulação, se dá em formatos adaptáveis aos dispositivos móveis e à internet, atendendo a modelos de comunicação que sejam adequados ao novo ecossistema midiático. Para Lévy (1996), o espaço virtual cria nova lógica para a velocidade e outros meios de interação são instaurados. Há multiplicação de espaços, possibilitando que os indivíduos transitem de um nó ao outro da rede, não somente de espaços geográficos, mas de espaços virtuais. Tais espaços virtuais "se metamorfoseiam e se bifurcam aos nossos pés, forçando-nos à heterogênese” (p. 23).

\section{Segmentação: marcas do Sertanejo}

A programação da emissora, no ar 24 horas pela internet, é essencialmente sertaneja, não havendo concessão de espaço a outros gêneros. As músicas disponibilizadas pela internet estão concentradas no country americano, sertanejo gospel, sertanejo universitário, sertanejo de raiz e sertanejo de amor, entre outras variaçóes, como são intituladas pela própria rádio. Já pelo WhatsApp, a programação segue uma rotina pré-determinada como, por exemplo, às segundas-feiras é enviado o programa Love Sertanejo; às quartas a rádio toca música de raiz ou sertanejos antigos e, às sextas, as canções são mais descontraídas. E todos os dias, às $18 \mathrm{~h}$, a tradicional Ave Maria é cantada por Paula Fernandes, cantora sertaneja mineira.

A opção pelo sertanejo segue a linha da preferência pelo gênero no país. Levantamento realizado em 2016 pelas plataformas Spotify e Deezer apontou que, no Brasil, o gênero sertanejo domina os principais rankings de músicas executadas, cantores, cantoras e duplas 5 . E traz informaçôes ainda sobre a ascensão do chamado "sertanejo feminista", com foco nos desencontros amorosos cantados por mulheres. Um outro levantamento, desta vez do Instituto Crowley, responsável por monitorar as emissoras brasileiras de rádio, aponta que entre as dez músicas mais tocadas no país em 2016, todas são sertanejas ${ }^{6}$.

Pesquisador da gênese do sucesso da música sertaneja no Brasil, Edvan Antunes (2012) explica que o gênero veio preencher uma lacuna deixada pela desaceleração do rock nacional, do axé e do pagode. Ele afirma que as primeiras gravaçóes caipiras são dos anos 1920 e que hoje essas músicas amadureceram e se consolidaram no mercado.

$\mathrm{Na}$ transmissão realizada às $11 \mathrm{~h} 48$ do dia 15 de março de 2017, por exemplo, percebemos diversos elementos que, embora enviados separadamente aos usuários por conta da própria economia do WhatsApp, representam um conjunto, conforme imagem a seguir, em uma sequência lógica audioverbovisual que, como explicado no início deste texto, permite experiências diversas de modos de escuta e de relacionamento entre produtores, conteúdo e ouvintes. 


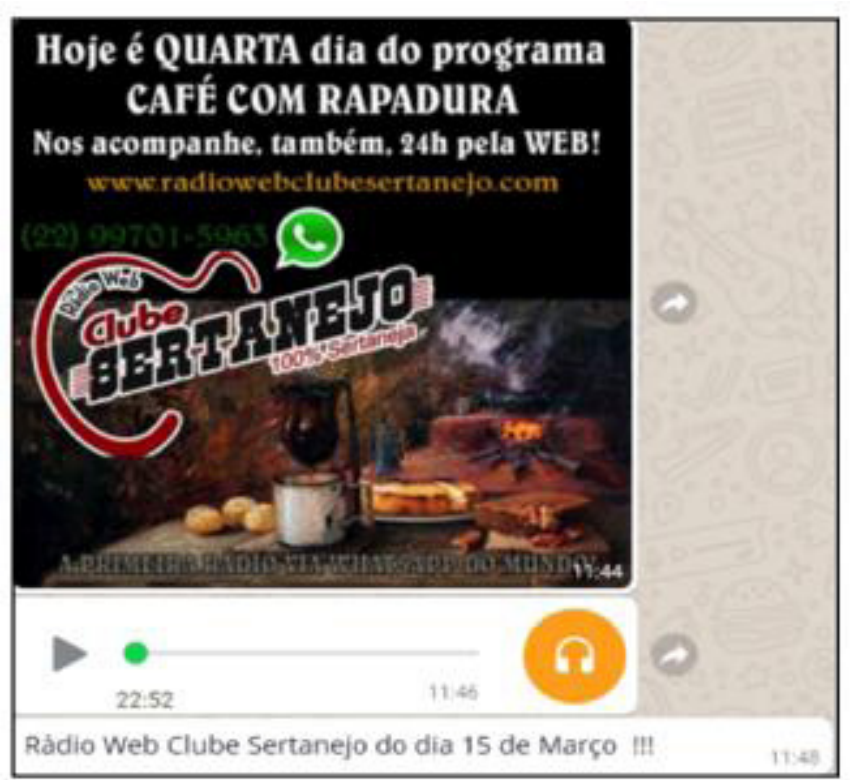

Figura 2: Programação Rádio Web Clube Sertanejo

Fonte: Captura WhatsApp

A imagem (Figura 2) traz um cenário cuja ambiência remete a imaginários de uma cultura visual sertaneja, como o fogão a lenha, a caneca esmaltada para receber o café, que chega quentinho do coador de pano, a panela por onde se pode ver a fumaça subindo, e também pães de queijo e bolos. Além da valorização desse universo sertanejo, o anúncio traz muitas informações associadas à divulgação da rádio tanto pelo aplicativo quanto pelo site na internet. Há ainda uma marcação temporal a partir da indicação do dia da semana e do programa a ser transmitido, ambos em letras maiúsculas, para chamar a atenção do usuário, em uma associação direta com a logomarca da rádio e o reforço da segmentação por meio do slogan "100\% sertaneja". Para finalizar o texto verbovisual, a assinatura "A PRIMEIRA RÁDIO VIA WHATSAPP DO MUNDO” novamente com o uso de maiúsculas. Essas inscrições assumem a simbologia não só do direcionamento para um público supostamente imaginado, mas de uma tentativa de se firmar como uma iniciativa inédita e pioneira.

O relinchar de um cavalo e o mugido de uma vaca, associados ao grito de um suposto peão boiadeiro, sugerem ao ouvinte uma paisagem sonora típica do campo no programa cujo áudio, com a imagem do play pode ser visualizada na Figura 2. A entonação forjada para assimilar-se aos locutores de rodeios é perceptível na voz do locutor, que parece escolher um estilo no qual há uma miscelânea de elementos da fala coloquial com expressóes típicas supostamente de moradores de algumas zonas rurais. Além de evidenciar, intencionalmente, os erros de concordância entre os elementos das frases, esse estilo revelaria determinadas expressôes presentes nas músicas sertanejas e que dão conta de estereótipos sobre o discurso de pessoas que vivem no campo. Antes de tocar a música, por exemplo, o locutor anuncia: "essa nóis toca aqui" ou ainda "hoje é dia de tocar aquela música que nóis gosta”. 
A saudação aos ouvintes é repetida nessa emissão, assim como em todas as que acontecem diariamente, com o bordão: "Brutas e Brutos", um cumprimento marcadamente da vertente de um subsegmento do Sertanejo, o Sertanejo Bruto. Seriam características desse estilo o romantismo, com voz grave, ausência de delicadezas e um discurso que não se preocupa em negar o machismo ${ }^{7}$.

A programação ainda inclui um Momento de Reflexão. No dia 14 de março, por exemplo, às $9 \mathrm{~h} 28$, foi enviado com vídeo (Figura 3) em que uma pessoa chamada Ivan Saraiva fala sobre os valores da paz. Ele usa uma blusa com a inscrição "Fé" e oferece gratuitamente aos ouvintes um DVD duplo sobre o assunto, que será enviado pelos Correios. O interessado deve ligar para (12) 2127-3121, fornecer nome e endereço e, assim, ganha o DVD. Em seguida, ele cita alguns versículos bíblicos e faz uma reflexão religiosa. O vídeo tem 3 minutos e 47 segundos. Ao final, é exibido o endereço www.novotempo.com/estaescrito, site da Rede Novo Tempo de Comunicação. Segundo o proprietário da emissora, esses vídeos nunca são repetidos.

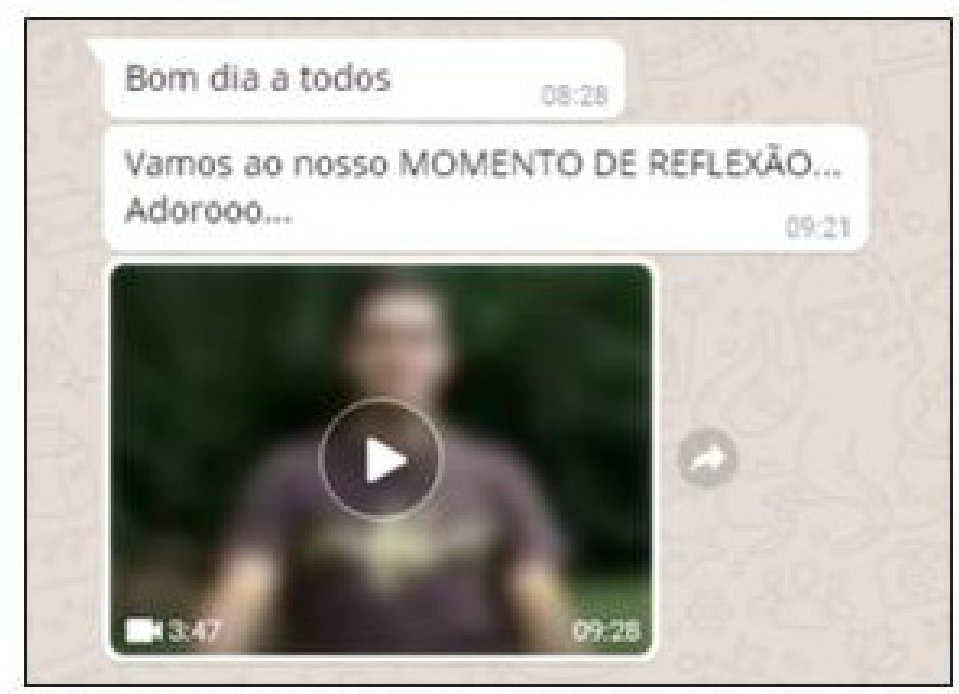

Figura 3: Momento de Reflexão em 14/03/2017 às 9h28

Fonte: Captura WhatsApp

A emissora também utiliza uma das mais tradicionais ferramentas da comunicação eletrônica, tanto no WhatsApp, quanto nas outras plataformas: a prestação de serviço e o engajamento em campanhas sociais (Figura 4). Segundo o Ibope $\mathrm{Media}^{8}$, o conteúdo preferido pelo público de rádio é notícia e prestação de serviço, consumido por $65 \%$ da audiência; em segundo lugar, está a música, preferência de 47\%, seguida de conteúdo religioso, $19 \%$, esportes, $18 \%$, variedades e humor, $18 \%$, opinião, $11 \%$ e participação de ouvintes, 7\%. A Rádio Web Clube Sertanejo, portanto, organiza sua programação de forma inteligente ao centrar seu propósito comunicativo em música e prestação de serviço. 

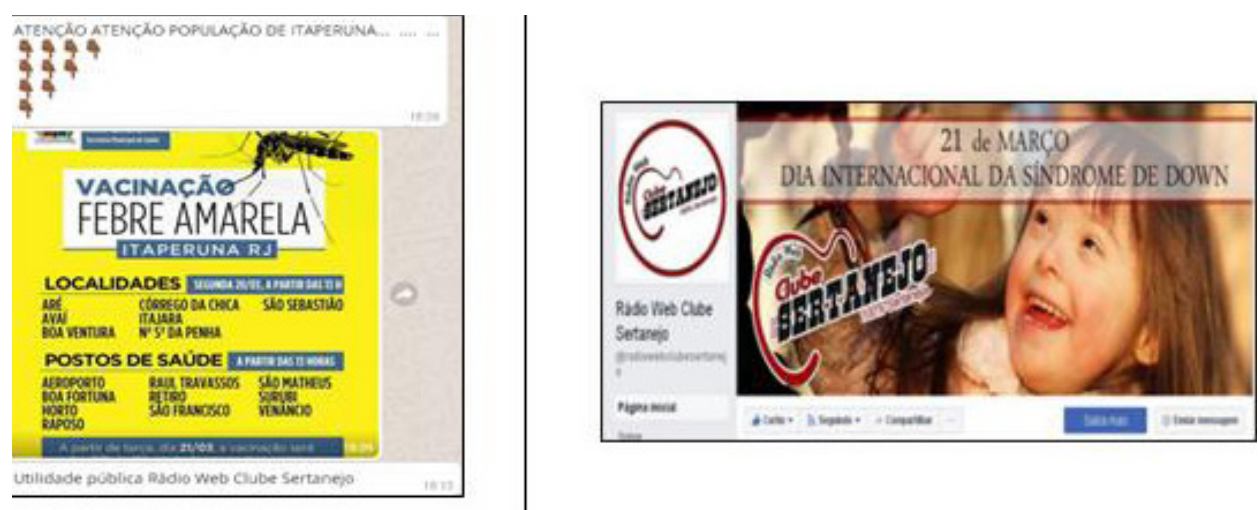

Figura 4: Prestação de serviço e campanhas sociais

Fonte: Captura WhatsApp

\section{Tensões entre modos de produção, circulação e empoderamento sutil do ouvinte}

Em média, a Rádio Web Clube Sertanejo possui pouco mais de 15.500 ouvintes, somando-se todas as plataformas de emissão, sendo 12 mil ouvintes pela internet e 3.506 pelo WhatsApp. A transmissão da programação, via WhatsApp, é gravada - geralmente um pequeno bloco com músicas, comerciais e publicidade institucional da emissora - e, logo em seguida, o arquivo é enviado. É interessante observar que a emissora avisa aos ouvintes quando uma gravação está sendo realizada e, pouco tempo depois, o arquivo é enviado, como pode ser observado nas imagens que compóem a Figura 5, a seguir:

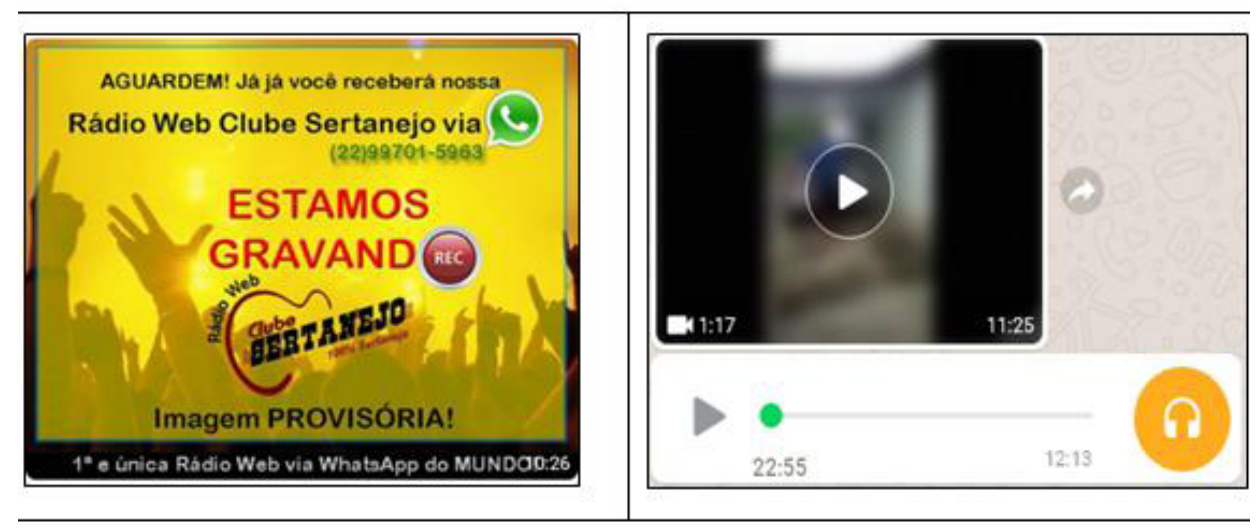

Figura 5: Programação da rádio via WhatsApp

Fonte: Captura WhatsApp

O compartilhamento do arquivo se dá por lista de transmissão do WhatsApp, um sistema de listas de destinatários pré-determinados pelo qual são enviadas transmissóes repetidamente, sem precisar selecionar os contatos novamente toda vez que for feita uma nova remessa. Quando é enviado um arquivo para uma lista de transmissão, todos os destinatários recebem a mensagem, que aparece na tela de conversas. E se alguém 
responder, a mensagem é enviada apenas ao remetente e não aos demais destinatários. Ou seja, não há interação entre os usuários do aplicativo. Como as listas têm número limitado de membros, a Rádio Web Clube Sertanejo trabalha com 15 listas no total, cada uma delas com 250 ouvintes.

Não é novidade pensar que a proposta sonora deve dialogar com as características que fazem parte das plataformas comunicativas, estabelecendo um espaço multidirecional e simultâneo em que o rádio apresenta ao usuário a capacidade de interagir com o conteúdo de mídia. No caso da rádio aqui analisada, por exemplo, o primeiro contato estabelecido com a emissora é feito pelo ouvinte que, via WhatsApp, deve enviar nome, sobrenome e cidade. Ao tomar esta iniciativa o ouvinte assume a decisão de acompanhar a programação da emissora; é dele a escolha de "assinar" aquela lista de transmissão. A resposta da rádio ao pedido do ouvinte é quase imediata, como mostra a Figura 6, com uma sequência de tentativas de demonstrar a valorização da participação do ouvinte. É feita uma solicitação de informaçóes sobre como a pessoa conheceu a emissora, além de instruçôes sobre como proceder para acessar a programação. Há também um pedido de envio de foto e a saudação com o slogan dito pelo DJ: "Luxo querida... que seja bem, vinda", seguido do pedido de desculpas por não ter atendido à ligação do WhatsApp, pois a equipe estava gravando a programação.

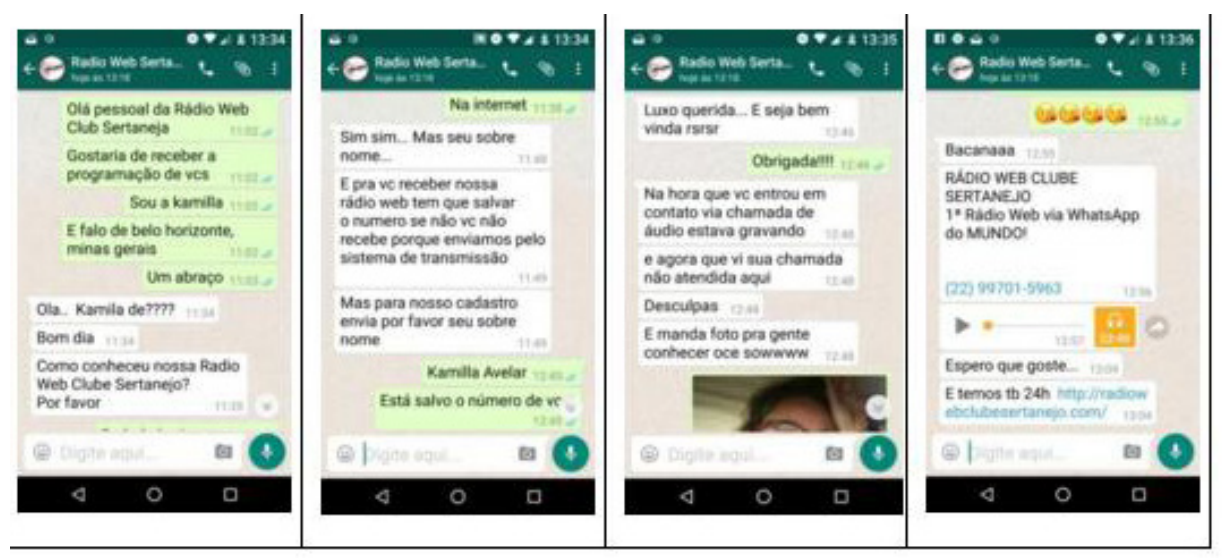

Figura 6: Primeiro contato Rádio Web Sertaneja Fonte: Captura WhatsApp

O WhatsApp talvez seja o modo de transmissão e de circulação mais personalizado adotado pela emissora, que optou, ainda, pelo site (http://radiowebclubesertanejo.com) e um aplicativo próprio abrigado no integrador RadiosNet, além de acesso pelo site de uma empresa parceira (www.cowboy120x.com.br). A emissora possui perfil no Facebook (262 seguidores) e Instagram (687 seguidores). Sobre o pequeno número de seguidores nas redes sociais, Ademar Nunes Filho avalia que o ouvinte da emissora "quer mesmo é ouvir música e receber notícias".

O idealizador da Rádio Web Clube Sertanejo elabora uma proposta de categorização das dinâmicas possíveis entre a emissora e o público por 
meio das várias plataformas de emissão: "Pelo WhatsApp, parecemos amigos; pelo site, é uma relação mais profissional; no Facebook, estamos ainda começando nesta plataforma e, por enquanto, está sendo bem bacana”. Ele diz que o celular da rádio "é uma loucura" e que de vez em quando tem que "dar uma limpeza nos contatos" por causa do grande volume de destinatários da emissora. $\mathrm{Na}$ entrevista, Ademar relatou um dos muitos casos vividos à frente dos microfones:

Temos uma ouvinte bem antiga, da época em que éramos somente via WhatsApp, e
em menor tempo. Bom, essa senhora nunca pediu música, porém é bem participativa.
E um dia resolveu me ligar para pedir uma música. Simplesmente ela pediu pra tocar
qualquer música do Roberto Carlos rsrsrs... E respondi: Senhora, nunca reparou que
a rádio só toca sertanejo? Ela automaticamente respondeu com a voz meio engraçada:
Sim, mas quem sabe Roberto Carlos tem uma música no estilo sertanejo e eu náo sei...
E demos ótimas risadas!".

Se, por um lado, há trocas de mensagens iniciais entre o usuário do WhatsApp e a rádio, as publicaçôes da emissora no Facebook são limitadas, normalmente, a chamadas para a programação e para os eventos e promoçóes da rádio. Desperta a atenção o retorno quase nulo do público, com uma ou duas curtidas nos posts e quase nenhum comentário.

No Instagram também não há qualquer referência à transmissão por WhatsApp e, nesta plataforma, o slogan é outro: "Rádio Web 100\% Sertaneja". Há também o link para o site e a informação da disponibilidade do aplicativo da emissora. Como rodapé fixo, há um pedido para que os usuários sigam os parceiros comerciais da emissora, acompanhado de uma lista com os respectivos endereços de perfis. A participação do público é também muito pequena no Instagram (Figura 7), com poucas curtidas e quase nenhum comentário nas postagens, que se resumem a chamadas institucionais ou da programação.

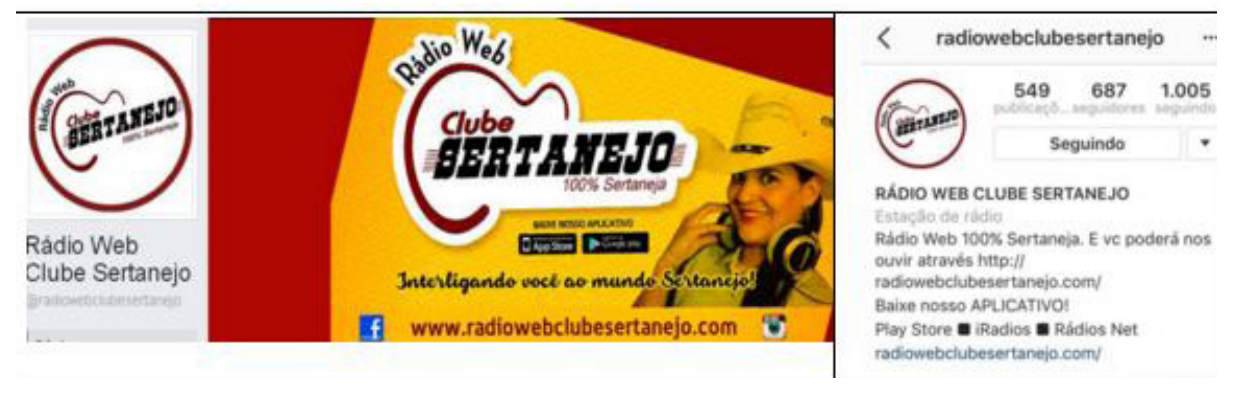

Figura 7: Perfil da rádio no Facebook e Instagram

Fonte: Captura Facebook e Instagram

Talvez esse possa ser considerado um dos exemplos do comportamento das audiências, que teria mudado radicalmente desde a implantação da internet. Os usuários das redes sociais online, que constituem o público de emissoras como essa, parecem querer receber produtos em suas telas com exclusividade, de maneira imediata e gratuita (GONZÁLEZ; PORTAS, 
2017). O que os autores registraram a partir de reflexóes teóricas é percebido, de um ponto de vista pragmático, pelo proprietário Rádio Web Clube Sertanejo, que acredita que o público da rádio deseja, prioritariamente, ouvir música sem se preocupar em interagir pelas redes sociais.

\section{Modelo de negócios}

O sintagma modelo de negócio pode ser compreendido como a lógica com que "uma determinada organizaçáo cria, distribui e captura valor" (OSTERWALDER; PIGNEUR, 2010, p. 14) ou como uma proposta de valor com soluçóes por meio de produtos e serviços que possam satisfazer as necessidades dos clientes de uma maneira melhor que o concorrente (MAJÓN; VARA-MIGUEL; DÍAZ-ESPINA, 2016). O modelo de negócios é fundamental para a sustentabilidade de projetos como rádios em ambientes digitais. $\mathrm{O}$ que se percebe, no entanto, é que eles não necessariamente são estudados e planejados com antecedência, antes do lançamento do produto. Parece-nos que os projetos em ambientes digitais e em dispositivos móveis carecem de formatos que extrapolam os modelos tradicionalmente adotados pelas emissoras comerciais hertzianas e que consigam viabilizar todos os processos relacionados à produção e circulação de produções em áudio nestes ambientes.

No nosso estudo de caso, por exemplo, o modelo de negócios foi um dos temas da entrevista realizada com o idealizador da emissora. Ele afirmou que os recursos gerados pela emissora são suficientes para arcar com as próprias despesas, mas que ainda não há registro de lucro. A Rádio Web Club Sertanejo se sustenta financeiramente por meio de parceiros comerciais, muitos deles desde os primeiros tempos, quando a estação realizava transmissóes somente pelo WhatsApp. Há contribuiçôes financeiras e um sistema de permuta. Atualmente, a rádio tem pelo menos 11 parcerias publicitárias?.

Apesar de a Rádio Web Clube Sertanejo buscar novas propostas de emissão, no tocante ao modelo de negócio, repete as velhas fórmulas da mídia tradicional. A maneira como a emissora cria, distribui e captura valor em nada difere das demais emissoras em plataforma multimídia e até das rádios hertzianas. A rádio depende visceralmente da publicidade para sobreviver, como acontece no rádio brasileiro desde os anos 1930. Na entrevista realizada com o proprietário da emissora e na observaçáo realizada por estas pesquisadoras, não há qualquer indício de avanço na configuração da cadeia de valor e, consequentemente, no modelo de negócio da rádio.

Costa (2014) aponta que a mídia tradicional se apoia em uma operação impulsionada por quatro zonas muito bem definidas que, na Rádio Web Clube Sertanejo, são claramente identificáveis: 1. Produção de conteúdo; 2. Administração, finanças, recursos humanos; 3. Comercialização; 4. Circulação. $\mathrm{Na}$ emissora, a pequena equipe, composta pelo casal que idealizou o projeto, produz o conteúdo, gerencia o negócio, vende a publicidade e realiza a transmissáo, tudo isso sem levar em conta as novas possibilidades oferecidas pelo meio digital para geração de uma cadeia de valor que não seja sustentada apenas pela venda de comerciais. 
A partir do estudo elaborado pela plataforma dosdoce.com para os novos modelos de negócio da era digital, é possível apontar que a rádio adota dois modelos de transmissão: 1. Open access, ou acesso livre: pelo site, o usuário tem acesso a todos os conteúdos, sem qualquer restrição ou imposição de pagamento; 2. Assinatura: nas transmissóes pelo WhatsApp há a exigência de uma adesão à emissora, mas sem qualquer ônus para o usuário. O modelo de negócio utilizado pela emissora é, portanto, o chamado Publicidade Inserida, que consiste em oferecer conteúdo gratuito, mas com publicidade que, no caso da emissora pesquisada, parece ser de interesse concreto para os seus usuários.

Além da publicidade, a emissora utiliza a também tradicional permuta, uma das formas mais antigas de sustentabilidade no rádio. A literatura relata casos de pequenas emissoras que sobrevivem quase que totalmente com permutas diversas, beneficiando patróes e empregados com produtos e serviços em troca de inserção comercial. Na permuta geralmente não há dinheiro envolvido, apenas uma valoraçáo do que cada parte oferece para o fechamento do acordo.

Do ponto de vista da publicidade institucional, registramos que as escolhas, tanto da garota propaganda quando da simbologia para a maioria das campanhas, se dá a partir de referências pessoais do casal que ancora todos os processos de produção, circulação e de negócios da emissora. Um dos símbolos utilizados na publicidade institucional da rádio é uma muleta, em uma referência subliminar à discussão sobre pessoas com deficiência e acessibilidade, que está diretamente relacionada à condição pessoal do dono da rádio. Ademar explica que ele usa uma muleta para se apoiar ao caminhar, pois foi vítima de erro médico há quatro anos ao se submeter a uma cirurgia na coluna: "Por isso na vinheta tem a frase 'Aqui a muleta mandaaaa...' Sempre uma das primeiras vinhetas inicia com o nome da rádio, aí vem a muleta, manda e logo em seguida entro com Aowwwww Misericórdiaaa..." A esposa do idealizador da rádio, Khaty Leonardo Pereira Nunes, além de contribuir com as atividades diárias da rádio, também atua como modelo na publicidade institucional da emissora.

\section{Conclusão}

O ambiente digital proporciona experiências a pessoas comuns para criação, produção, transmissão e circulação de conteúdos em áudio que muito se assemelham às emissoras hertzianas. Por outro lado, demandam estruturas leves, baixos investimentos e permitem que os homens ordinários, até bem pouco tempo, ouvintes de emissoras, idealizem e façam a implantação de seus próprios projetos, explorando sites, redes sociais e aplicativos em dispositivos móveis.

A segmentação da programaçáo seria, para projetos como esses, um pilar importante que facilita os processos de produção e circulação realizados por equipes compostas por poucas pessoas, sem vivência profissional anterior em emissoras de rádio, mas que transformam os seus modos de ver e de estar no mundo em conteúdos a serem consumidos pelos ouvintes usuários das plataformas digitais. 
Para além dos desafios técnicos e tecnológicos associados aos próprios recursos do ambiente digital, estáo postos pelo menos dois grandes desafios do ponto de vista do relacionamento com o ouvinte e do modelo de negócios escolhido pela emissora. Se por um lado percebemos a valorização do ouvinte e a tentativa de criar uma ambiência na qual ele se sinta envolvido, por outro, há ainda pouca exploração de interaçôes mais efetivas, com a participação ativa na programação e na troca com os demais usuários. O ouvinte se sentiria empoderado em dinâmicas nas quais ele é "recebido" no aplicativo, demandado a responder perguntas pessoais e a participar de uma conversa direta com o proprietário a emissora. Essas dinâmicas, no entanto, náo dariam conta de uma lógica colaborativa, típica dos ambientes digitais, na qual seria dado ao ouvinte o status de co-produtor da emissora.

A nosso ver, esse empoderamento, que nos parece sutil, apresentaria reflexos diretos no desenvolvimento dos modelos de negócios. Esses também estariam repetindo grande parte dos modos tradicionais de negociação de espaço na programação, mas que garantiriam a exploração dos ambientes digitais e suas múltiplas possibilidades de sustentabilidade destas transmissôes, que se autointitulam emissoras de rádio.

\section{Bibliografía}

ANTUNES, Edvan. De caipira a universitário: a história do sucesso da música sertaneja. São Paulo: Matrix Editora, 2012.

AVELAR, Kamilla; PRATA, Nair. O branded content como estratégia comunicativa no rádio corporativo. Anais do XXXIX Congresso Brasileiro de Ciências da Comunicação, São Paulo, 2016. Disponível em: http:// portalintercom.org.br/anais/nacional2016/resumos/R11-0023-1.pdf. Acesso em: 3/4/2017.

CERTEAU, Michel de. A invenção do cotidiano: Arte de fazer. Rio de Janeiro: Vozes, 2014.

COSTA, Caio Túlio. Um modelo de negócio para o jornalismo digital. Revista de Jornalismo ESPM. Abr-jun. de 2014.

GONZÁLEZ, Aurora; PORTAS, Mercedes. Sobre los nuevos modelos de negocio en las actividades radiofónicas. Revista de la Asociación Española de Investigación de la Comunicación, [S.I.], v. 4, n. 7, p. 1-5, mar. 2017. ISSN 2341-2690. Disponível em: <http://www.revistaeic.eu/ index.php/raeic/article/view/104>. Acesso em: 23 mar. 2017.

LEVY, Pierre. O que é o virtual? São Paulo: Editora. 34, 1996.

MAJÓN, Idoia; VARA-MIGUEL, Afonso; DÍAZ-ESPINA, Carolina. Innovación, modelos de negocio y medición de audiencia ante los nuevos retos del marcado de la comunicación. In: CHALEZQUER, Charo; AVILÉS, José; MARTÍNEZ-COSTA, Maria del Pilar (coord.). Inovación y desarrollo de los cibermedios en España. Pamplona: EUNSA, 2016. p. 31-39. 
MARTÍNEZ-COSTA, Pilar; PRATA, Nair. O rádio em busca da sua audiência: rumo a uma escuta diversificada e multiplataforma. Anais do XXXIX Congresso Brasileiro de Ciências da Comunicação, São Paulo, 2016. Disponível em: http://portalintercom.org.br/anais/nacional2016/ resumos/R11-1530-1.pdf. Acesso em: 9/3/2017.

MENDONÇA, Carlos. Experiência e Significação. In: LEAL, Bruno; MENDONÇA, Carlos GUIMARÃES, César. Entre o sensivel e o comunicacional. Belo Horizonte: Autêntica Editora, 2010, p. 179-188.

ORTIZ SOBRINO, Miguel Ángel. De la post-radio convergente a la radio híbrida. Revista de la Asociación Española de Investigación de la Comunicación, [S.1.], v. 4, n. 7, p. 1-5, mar. 2017. ISSN 2341-2690. Disponível em: http://www.revistaeic.eu/index.php/raeic/article/view/104. Acesso em: 23/3/2017.

OSTERWALDER, Alexander; PIGNEUR, Yeves. Business Model Generation. New Jersey: John Wiley\& sons, 2010.

PESSOA, Sônia. Estética da diferença: contribuiçôes ao estudo da deficiência e das redes sociais digitais como dispositivos de mise en scéne. Tese (Doutorado) - Universidade Federal de Minas Gerais, Faculdade de Letras, Belo Horizonte, 2015. Disponível em: <http://150.164.100.248/ poslin/defesas/1634D.pdf>. Acesso em: 30/3/2017.

PESSOA, Sônia. O empoderamento sutil do ouvinte no radiojornalismo: os desafios de uma cultura além da escuta. Anais do XXXIX Congresso Brasileiro de Ciências da Comunicação, São Paulo, 2016. Disponível em: http://portalintercom.org.br/anais/nacional2016/resumos/R11-0428-1. pdf. Acesso em: 20/3/2017.

PRATA, Nair; MARTINS, Henrique. A webradio como business. Intercom - Sociedade Brasileira de Estudos Interdisciplinares da Comunicação. Anais do XXXIII Congresso Brasileiro de Ciências da Comunicação, Caxias do Sul, 2010. Disponível em: http://www.intercom.org.br/papers/nacionais/2010/resumos/R5-0322-1.pdf. Acesso em: 3/4/2017.

Rádio corporativa: a segmentação sob encomenda como modelo de negócio. Anais do XXXVIII Congresso Brasileiro de Ciências da Comunicação, Rio de Janeiro, 2015. Disponível em: http://portalintercom.org.br/anais/nacional2015/resumos/R10-1579-3.pdf. Acesso em: 3/4/2017.

SALDANAA, Inaki. How the new business models in the digital age have evolved. Disponível em: http://www.dosdoce.com/2016/03/04/how-the-new-business-models-in-the-digital-age-have-evolved. Acesso em: 8/3/2017. 


\section{Notas}

1. Disponível em: <file://C:/Users/User/Downloads/Pesquisa\%20Brasileira\%20 de\%20M\%C3\%ADdia\%20-\%20PBM\%202016.pdf> Acesso em: 20 jan. 2017.

2. Disponível em: <http://www.perkons.com/upload/tiny_mce/arquivos/ 260813mobileconsumer.pdf>. Acesso em: 10 jan. 2016.

3. Disponível em: <http://blog.opinionbox.com/opinionbox/>. Acesso: 23 mar. 2016.

4. Disponível em: <http://blog.opinionbox.com/opinionbox/>. Acesso: 23 mar. 2016.

5. Disponível em: <http://www.diariodepernambuco.com.br/app/noticia/viver/2016/ 12/18/internas_viver,680660/a-musica-em-2016-sertanejo-e-preferencia-nacional-emradios-e-streami.shtml>. Acesso em: 22 abr. 2017.

6. Disponível em: <http://www.diariodepernambuco.com.br/app/noticia/viver/2016/ 12/18/internas_viver,680660/a-musica-em-2016-sertanejo-e-preferencia-nacional-emradios-e-streami.shtml>. Acesso em: 22 abr. 2017.

7. Disponível em:<http://blognejo.com.br/o-sertanejo-bruto-e-a-bola-da-vez/>. Acesso em: 27 abr. 2017.

8. Disponível em http://www.meioemensagem.com.br/home/midia/2015/08/05/ prestacao-de-servico-fortalece-o-radio.html Acesso: 28 abr. 2017.

9. Equoterapeuta Viviani Tevez, Life Center Academia, Clínica de Olhos do Dr. Afonso Travassos, Vss Imagens, Mazza GM, Drogaria Preço Baixo, Cowboy 120x Moda Country, Extreme Som, Veículos di Bandas, Silvana Confecçôes e Escritório MSF. 